\title{
Literacy: From the Perspective of Text and Discourse Theory
}

\author{
Danielle S. McNamara \\ Arizona State University \\ Correspondence regarding this article should be addressed to Danielle S. McNamara, Psychology \\ Department, Arizona State University, PO Box 871104, Tempe, AZ 85287-1104. \\ E-mail: dsmcnamara1@gmail.com

\begin{abstract}
Rod Roscoe
Arizona State University

Correspondence regarding this article should be addressed to Rod Roscoe, Human Systems Engineering, The Polytechnic School, Arizona State University, 7271 E. Sonoran Arroyo Mall, Mesa, AZ 85212.

E-mail: rod.roscoe@asu.edu
\end{abstract}

\section{Laura Allen \\ University of New Hampshire}

Correspondence regarding this article should be addressed to Laura Allen, Psychology Department, University of New Hampshire, 468 McConnell Hall, 15 Academic Way, Durham, NH 03824.

E-mail: laura.allen@unh.edu

\begin{abstract}
Renu Balyan
Arizona State University

Correspondence regarding this article should be addressed to Renu Balyan, Information Technology, The Polytechnic School, Arizona State University, Sutton Hall,6049 S Backus Mall, Mesa, AZ 85212.

E-mail: renu.balyan@asu.edu
\end{abstract}

\section{Kathryn S. McCarthy \\ Georgia State University}

\begin{abstract}
Correspondence regarding this article should be addressed to Kathryn S. McCarthy, Department of Learning Sciences, Georgia State University, College of Education and Human Development, P.O. Box 3978, Atlanta, GA 30302.E-mail: kmccarthy12@gsu.edu
\end{abstract}

\begin{abstract}
Literacy is a critically important and contemporary issue for educators, scientists, and politicians. Efforts to overcome the challenges associated with illiteracy, and the subsequent development of literate societies, are closely related to those of poverty reduction and sustainable human development. In this paper, the authors examine literacy from the lens of text and discourse theorists who focus on the higher-order comprehension processes involved in literacy. Discourse processing models make the assumption that comprehension emerges from the construction of a mental model of the text, which relies on the reader generating inferences to connect ideas within the text and to what the reader already knows. The article provides a broad overview of the theoretical models that drive research on text comprehension and production, as well as how this research shapes literacy instruction and effective interventions. The authors focus on two interventions with proven success in improving deep comprehension and writing, iSTART and the Writing Pal. Increasing literacy across the world call for a greater focus on theory driven strategy interventions to be integrated within classrooms and community at large.
\end{abstract}

Keywords: literacy, reading, writing, discourse theory, comprehension, strategies, interventions 
Literacy has been defined as a "set of instrumental reading, writing and math skills, as the ability to perform various life tasks using these skills, as a set of cultural practices encompassing reading, writing and calculation or as a process of obtaining critical knowledge of and reflecting on the world and one's place within it" (Walter, 1999). Literacy is a critically important and contemporary issue for educators, scientists, and politicians. Efforts to overcome the challenges associated with illiteracy, and the subsequent development of literate societies, are closely related to those of poverty reduction and sustainable human development (Cree, Kay \& Steward, 2012). Strong literacy skills are widely recognized as essential for surviving and thriving in modern society: a more literate population empowers nations to participate and compete on a global scale. At the individual level, literacy is considered essential to individuals being 'more empathetic, innovative, achievement-oriented, cosmopolitan, media- and politically-aware, aspiring to schooling, and accepting of technology' (Graff, 2017, 1987; Verhoeven, 1994). At the societal level, 'literacy is said to correlate with economic growth and industrialization, wealth and productivity, political stability and participatory democracy, urbanization, consumption, and contraception' (Graff, 2017, 1987; Verhoeven, 1994). Literacy is a human right; it is also key to achieving many developmental goals, be it improved nutrition and health, increased productivity and poverty reduction, enhanced political participation, empowerment of women, or sensitization to environmental issues. Underlying all of these benefits of literacy is perhaps the most critical aspect of literacy - it provides individuals the opportunity to learn and share information with others (Hanemann, 2015a, b).

The purpose of this paper is to examine literacy from the lens of text and discourse theories. In particular, we seek to first describe the current state of literacy in contemporary society and describe basic perspectives on literacy. We then provide a broad overview of the theoretical models that drive research on text comprehension and production, as well as how this research shapes literacy instruction. Finally, we conclude with a discussion of future directions regarding literacy interventions.

\section{Literacy Levels across the World}

Broadly speaking, the majority of the world is literate - only $15 \%$ of the total population is estimated to lack sufficient literacy skills to function in society. Indeed, in the $21^{\text {st }}$ century, most regions of the world have reached levels of 85 to $95 \%$ literacy rates. In Russia, literacy rates are estimated as high as 99.7\%; and in South Africa, approximately 94\%; (UNESCO, 2015). Importantly, this high literacy rate is relatively recent. Various sources estimate that only $15 \%$ of the world population were able to read and write 200 years ago (Van Leeuwen \& van Leeuwen-Li, 2014; van Zanden et al., 2014). The last 50 years have seen a remarkable improvement in literacy, particularly amongst youth (Genlott \& Grönlund, 2013). Half a century ago, approximately one quarter of all youth in the world lacked basic literacy skills; by 2016, this number had decreased to only 10\% (UNESCO Institute for Statistics, July 2017) ${ }^{1}$.

Unfortunately, these estimates suggest that approximately 750 million adults remain functionally illiterate in today's society, with particularly low literacy rates in concentrated populations in the world (UNESCO Institute for Statistics, July 2017) ${ }^{1}$. For example, South and Southeast Asia, the Middle East and North Africa, and SubSaharan Africa report basic literacy levels of around 60\% (van Zanden et al., 2014). Other areas of the world report literacy rates as low as 19 percent (UNESCO, 2015). In addition, many of those who have learned to read and write, do not make active or meaningful use of their literacy skills. There are millions of individuals who are considered "literate" but who do not possess a sufficient mastery of literacy to cope with even the most elementary tasks. There are many more people throughout the world who experience problems because they are not 'functionally' literate in relation to their environment. This may include immigrants who are living in a foreign language country, people with dyslexia, or those with visual impairments who do not have access to affordable reading resources in order to be able to make use of their literacy skills. These individuals can feel handicapped in coping with modern life situations, requiring ever more sophisticated literacy skills.

What is literacy? An important caveat to this discussion of literacy rates relates to the means through which "literacy" is defined. Estimated rates of literacy vary based on the assessments used, as well as individuals" interpretations of these definitions and corresponding assessments. For example, the PIRLS international literacy benchmarks include four achievement levels (Mullis, Martin, Foy, \& Drucker, 2012): low: can locate and retrieve information; intermediate: can make straightforward references; high: can make inferences and interpretations with text-based support; and advanced: can integrate ideas and in-formation across texts to provide reasons and explanations. According to these benchmarks, even the highest performing countries 
achieve scores of only $20 \%$ in the "advanced" category and $60 \%$ in the "high" category, and many have claimed that even these estimates may be inflated. Thus, despite claims that the majority of the world population might be considered "literate," there remains significant room for improvement in these skills.

Beyond the issues associated with literacy assessment, the very term - literacy - is used in various ways in the research literature and in practice. UNESCO defines a literate person to be someone "who can, with understanding, both read and write a short simple statement in everyday life" (UNESCO, 2008). Importantly, the word "literacy" has commonly been associated with basic, everyday reading processes (e.g., word recognition, phonics, and lexical decoding). However, reading is a complex activity that relies on a variety of processes, from recognizing letters and identifying words to processing the meaning of a full sentence and integrating textual information with prior domain knowledge. For example, Luke and Peter's (1997) "Four Literacy Resources model" specifies a set of practices in which children need to participate to become good readers:

a. breaking the code of written texts;

b. participating in understanding and composing meaningful written, visual and spoken texts;

c. using texts functionally; and

d. critically analyzing and transforming texts.

Indeed, effectively using literacy skills requires individuals to use their knowledge of the world and language, necessitating the knowledge and use of written language as a means of communication that goes beyond just breaking the code.

\section{Text and Discourse Theories of Reading}

Our objective here is to describe literacy from the perspective of text and discourse theories. Text and discourse researchers focus on the higher-order comprehension processes involved in literacy (Graesser, Gernsbacher, \& Goldman, 2003; Schober, Britt, \& Rapp, 2018). Take, for example, an excerpt from the Wikipedia entry on Quantum Physics:

In the mathematically rigorous formulation of quantum mechanics [...] the possible states of a quantum mechanical system are symbolized as unit vectors (called state vectors). Formally, these reside in a complex separable Hilbert space - variously called the state space or the associated Hilbert space of the system - that is well defined up to a complex number of norm 1 (the phase factor).

A proficient reader may recognize the individual words or accurately parse the sentence and be able to read the passage aloud. However, these fundamental skills do not guarantee that the reader will have understood this passage, or, perhaps more importantly, be able to use or apply this information in a new situation. Unless the reader has sufficient knowledge of the domain and topic, it is virtually impossible to make sense of this text, let alone understand the deeper meaning.

Constructing a Coherent Mental Model during Reading. Discourse processing models make the assumption that comprehension emerges from the construction of a mental model of the text. A mental model consists of a network of interrelated propositions that reflect the explicit information contained within a text (e.g., Kintsch, 1988; 1998). Accordingly, as a text is processed, each sentence sends out a retrieval signal that leads to the activation of semantically related propositions corresponding to prior discourse constituents and relevant prior knowledge (Myers \& O’Brien, 1998). The features of sentences that serve as retrieval signals involve nouns, verbs, and derived propositions (Kintsch, 1988) as well as morphological information (e.g., cohesion cues) that signal that any given sentence is related to prior discourse constituents (Graesser \& McNamara, 2011). Texts convey implicit situational relations to the prior discourse context (time, space, causality) and structural cues (comparison, descriptive, cause-effect) that also direct the reader to the need to establish relations between the current sentence and the prior context. These features are by no means uniformly represented across a text; as such, activation dynamically waxes and wanes as readers process a text (McNamara \& Magliano, 2009a; Myers \& O’Brien, 1998). Successful readers are sensitive to the dynamic changes of these features as they process a text. The end result of successful reading is a network of propositions (i.e., ideas) that reflects the relations derived by the reader, and ideally, those relations that were warranted by the intended structure of the texts. 
The Construction-Integration Model of Comprehension. Many contemporary discourse comprehension models found their roots in the Construction-Integration model of comprehension (Kintsch, 1998) and its predecessors (Kintsch \& van Dijk, 1978; van Dijk \& Kintsch, 1983). The Construction-Integration model claims that readers construct multiple levels of understanding including the surface structure, textbase, and situation model levels. The surface structure contains the explicit words and sentence structures from the text. If a reader constructs a mental model that is primarily dominated by a surface structure, they will only have a memory for the explicit words in the text. In the textbase level of the model, words and syntax in the surface structure are integrated to build a mental model of the text propositions. This level represents the general ideas and concepts contained in the text, including the gist. These generalizations yield a series of propositions that may be only loosely or inaccurately interconnected. It is impossible to include all of the information and relations explicitly within a text; thus, the activation and use of background knowledge is necessary to fill in the gaps and to add structure and stability to the network of concepts.

The third level of representation is referred to as the situation model. The situation model is a higher-level representation of text that is related to semantic meaning rather than specific words. This model contains not only the information from the text itself, but also links between these concepts and a reader's prior knowledge. Therefore, to establish a coherent representation of the text, individuals must integrate aspects of their knowledge, such as lexical and domain knowledge, with information explicitly provided in the text.

It is important to note that the representation that emerges after this construction-integration process is not necessarily equally composed of text-based and knowledge-derived information. For instance, it is possible for either the textbase or situation model to dominate the final mental representation. A primary assumption of the C-I model is that deep comprehension requires readers to process texts at multiple levels. A reader's mental representation of a text is more coherent to the extent that inferences are generated to create links between concepts explicitly conveyed in the text (i.e., the textbase) and connections to prior knowledge (i.e., the situation model).

In summary, according the Construction-Integration model of comprehension, reading involves processing the words and sentences in the text, activating related concepts, and generating a situation model, wherein background knowledge and experiences are integrated into the text for a specific purpose (Kintsch, 1998). As such, text comprehension processes are goal-oriented. If the purpose of reading is to remember the sounds of the words or to memorize individual sentences, that objective may be met, but this would not reflect meaningful comprehension. By contrast, consider a reader who is trying to learn from a text. This reader attempts to make connections between ideas in the text, and to what they already know -- the reader is working toward a coherent mental representation of the text (McNamara, 1997). The reader is seeking to achieve deep comprehension.

Generating Inferences is the Key to Comprehension. Coherent and durable mental models emerge through the construction of inferences (see McNamara \& Magliano, 2009, for a review of comprehension models). Indeed, ssuccessful comprehension depends on inference generation (Graesser et al., 1994; Kintsch, 1998; McNamara \& Magliano, 2009b). Inferences are necessary in order to integrate information from the text with prior knowledge and connecting ideas across the text. As such, general, world, and topic knowledge are crucial components to comprehension, and literacy. Readers who have more knowledge are more likely to generate inferences that connect new information to what they already know -- inferences form the glue that makes information stick. Readers who know more about the topic are more likely (and able) to generate inferences that connect new information to what they already know. In turn, stronger associations between ideas make them more memorable and comprehensible. Indeed, research indicates that prior knowledge is one of the strongest predictors of comprehension success (Dochy et al., 1999; Shapiro, 2004). Readers with more prior knowledge about the topic and the world in general are able to process information more quickly, remember more information, and ignore irrelevant information (e.g., Alexander, Kulikowich, \& Schulze, 1994, Bransford \& Johnson, 1972; Chiesi, Spilich, \& Voss, 1979; McNamara \& Kintsch, 1996; McNamara \& McDaniel, 2004).

There are a number of types of inferences involved in comprehension (see O'Brien, Cook, \& Lorch, 2015). These inferences can be characterized in two broad classes: bridging and elaborative (Singer, 1988). Bridging inferences involve establishing connections between explicit discourse constituents. Bridging can encompass low-level anaphor resolution or higher-level situational relations, such as causal, motivational, temporal, spatial, logical, and argumentative relations. Elaborative inferences, on the other hand, involve readers drawing upon knowledge from outside the text (Graesser \& Clark, 1985; Graesser et al., 1994; McNamara \& Magliano, 
2009b; Singer, 1988). Elaborative inferences can be generated based on existing generic knowledge of the world (e.g., schemas; Graesser \& Nakamura, 1982; O’Brien et al., 1988; Seifert et al., 1985), domain or topic specific knowledge (e.g., McNamara, 2001), or based on extemporaneous problem solving and reasoning about the text content (e.g., Trabasso \& Magliano, 1996).

\section{Strategies to Improve Comprehension}

Text and discourse theorists have emphasized the importance of strategies that promote inference generation while reading. Inferential processes can be supported by passive, memory-based processes (McKoon \& Ratcliff, 1998) or through active, strategic processing (Magliano et al., 1999; McNamara, 2004; McNamara \& Magliano, 2009a). One means of improving comprehension is by encouraging readers to engage in strategic inferencing. Indeed, many studies have demonstrated the benefits of reading strategy instruction (e.g., Baker, 1996; Baumann, Seifert-Kessell, \& Jones, 1992; Bereiter \& Bird, 1985; Hansen \& Pearson, 1983; Palincsar \& Brown, 1984, 1986; Yuill \& Oakhill, 1988). Such foundational studies emphasized the importance of strategies such as summarization, question asking, paragraphing, making bridging inferences, and elaboration (Rosenshine \& Meister, 1994; Rosenshine, Meister, \& Chapman, 1996; see McCrudden \& McNamara, 2017, chapter 4, for a brief review).

Promoting inference generation is key to reading strategy instruction (McNamara, 2007; Snow, 2002; Palincsar \& Brown, 1984, 1986). When paraphrasing, readers attempt to restate the text in more familiar terms (i.e., putting the text in their own words), and thus they are making connections between the text and familiar terms. Predicting occurs when readers attempt to anticipate upcoming text contents though thoughtful guesswork (e.g., expecting a new term to be defined in future sentences). This is most successful for familiar text such as narratives. When bridging, readers make inferences to connect current text information to prior text information, whereas elaborating involves the use of general knowledge, domain-specific knowledge, or logical reasoning to expand upon given text information. In turn, comprehension monitoring entails readers' self-assessments of their own text understanding. It is the process of being aware of one's own understanding and thus, it generally falls out of using effective reading strategies. Readers need to be at least somewhat aware of their level of understanding to use a strategy. And, the awareness of comprehension gaps ideally leads to the use of repair strategies.

One technique for promoting the generation of inferences is self-explanation. Self-explanation is the process of overtly explaining the deeper meaning of text while reading. Explanations are generally based on information contained in the discourse context and world knowledge. Self-explanation may be spontaneous (Chi, Bassok, Lewis, Reimann, \& Glaser, 1989) or in service of a specific goal (Magliano, Trabasso, \& Graesser, 1999; McNamara, 2004). Students who spontaneously self-explain understand more from learning materials and construct better mental models of content (Bisra, Liu, Nesbit, Salimi, \& Winne, 2018; Magliano et al., 1999; Trabasso \& Magliano, 1996; VanLehn, Jones, \& Chi, 1992).

Students can be taught to more effectively self-explain by leveraging active comprehension strategies during self-explanation McNamara, 2004; McNamara et al., 2004). Self-Explanation Reading Training (SERT; McNamara, 2004, 2017) is an instructional approach that leverages the benefits of self-explanation to improve students' strategic text processing and ultimately their comprehension. Students are provided with instruction and practice on how to use active reading comprehension strategies in combination with self-explanation while reading difficult expository texts. Few readers self-explain on their own and few self-explain well (Chi et al., 1994). Hence, to enhance this process, SERT combines self-explaining with five of the empirically-validated strategies: comprehension monitoring, paraphrasing, predicting, bridging, and elaborating. Students who use SERT better understand challenging science texts in comparison to students who are merely prompted to self-explain (McNamara, 2004, 2017; McNamara, O’Reilly, Best, \& Ozuru, 2006). Indeed, SERT is particularly effective for less skilled readers (Magliano et al., 2005) and readers who possess less relevant prior knowledge (McNamara, 2004, 2017).

SERT has been implemented within the Interactive Strategy Training for Active Reading and Thinking (iSTART), a technology-based support for comprehension literacy. iSTART implements and expands SERT within a gamebased, intelligent tutoring system(ITS) framework that includes online instructional tutorials and demonstrations for comprehension monitoring, paraphrasing, predicting, bridging, and elaborating. In addition, iSTART has been recently expanded to include training on fundamental comprehension strategies including summarizing 
and question-asking (Johnson et al., 2017; Ruseti et al., 2018a; 2018b). Across a variety of studies, iSTART has been found to facilitate self-explanation quality and reading comprehension for readers from middle school through adulthood and like SERT, is particularly helpful for low-knowledge and less skilled readers (Johnson, Guerrero, Tighe, \& McNamara, 2017; Magliano et al., 2005; McCarthy, Likens, Johnson, Guerrero, \& McNamara, 2018; McNamara, Levinstein, \& Boonthum, 2004; Snow, Jacovina, Jackson, \& McNamara, 2016).

An important component of iSTART's efficacy is that it enables multiple forms of strategy practice and feedback. First, in the coached practice module, students read a text and type self-explanations for target sentences. These explanations are automatically assessed via natural language processing (NLP) algorithms based on lexical and semantic indices. These algorithms identify the type(s) of strategies included in the students' responses, provide an overall quality score (from " 0 -Poor" to " 3 -Great"), and guide formative feedback on revising and improving their self-explanations (Jackson, Boonthum \& McNamara, 2015; Jackson \& McNamara, 2012; Panaite et al., 2018).

Second, iSTART also incorporates game-based practice to increase motivation and engagement (Jackson \& McNamara, 2013). Generative games allow students to earn points for writing high-quality self-explanations. Identification games ask students to read example self-explanations and earn points by identifying the demonstrated strategies. Points earned in these games can be "spent" to unlock additional games and customization features (e.g., personal avatars).

More recently, iSTART has been modified to increase personalized feedback. That is, iSTART has become more adaptive. An algorithm has been implemented that selects the difficulty of future texts based on the learner's prior performance. For instance, if a student consistently generates poor-quality self-explanations for a given text, the next assigned text will be easier (Balyan et al., 2018; Johnson et al., 2017). This adaptivity improves learning outcomes (McCarthy et al., 2018; under review) and increases students' perceptions of learning (Watanabe, McCarthy, \& McNamara, 2019), particularly for less-skilled readers.

\section{Text and Discourse Theories of Writing}

Writing is also a key component of literacy. Writing is a complex activity that entails nonlinear and iterative processes of idea generation, organization, translation, and refinement (e.g., Flower \& Hayes, 1981; Hayes, 2012; McNamara \& Allen, 2017; Olive, 2014). Writing also requires consideration of audience knowledge, needs, interests, and objections (e.g., Kellogg, 2008; Magnifico, 2010; McNamara \& Allen, 2017). Thus, perhaps unsurprisingly, researchers have documented a strong and multifaceted relationship between students' writing and reading skills (e.g., Allen, Snow, Crossley, Jackson, \& McNamara, 2014; Fitzgerald \& Shanahan, 2000; Graham et al., 2018; Shanahan, 2016). For instance, underlying both skilled reading and writing are fundamentals such as rich vocabulary knowledge, language fluency, and understanding of text structures and genres. In the case of reading, such knowledge enables decoding and comprehension of text. In the case of writing, the same knowledge empowers the organization and production of coherent text.

Compared to reading, there has been a lack of research and theory development on writing. There have been relatively few impactful theories of writing, and these theories have generally built upon each other, rather than approaching the process from a new lens. The most prominent model of writing defines writing as consisting of three distinct processes: planning, translating, and reviewing (Flower \& Hayes, 1981; Hayes, 1996, 2006; Hayes \& Flower, 1980). According to this model, planning involves idea generation and organization, as well as the setting of goals. Translation describes the act of translating ideas into written language, whereas the reviewing phase involves the evaluation and revision of the written text. The Flower and Hayes model of writing was the first to emphasize that these various writing phases were not necessarily linear (cf. Britton, Burgess, Martin, McLeod, \& Rosen, 1975; Roham, 1965). Rather, writing was argued to be a dynamic activity that involved rapid and continuous shifts amongst the independent phases.

Beyond these three phases, Flower and Hayes emphasized the important role of monitoring during writing, as well as the writer's use of the task environment and long-term memory to produce text content. Later revisions of this model included the additions of working memory, motivation, and affect (Hayes, 1996, 2006). The task environment was further delineated to include the social environment and the physical environment. Later depictions of the model dropped the explicit specification of the three stages (planning, translating, and reviewing), and adopted a stage theory model, placing working memory as the centerpiece of the model. 
The construct of working memory was consistent with the Baddeley (1986) working memory model, including phonological memory, a visuospatial sketchpad, and semantic memory, and was assumed to draw upon and be influenced by motivation and affect, cognitive processes, and long-term memory.

Despite its important contribution to the field, this model remains reliant on stage-theory models of cognition, which generally rely on discrete processing components (e.g., Hayes, 1996). The cognitive approach to writing often fails to consider the underlying subskills involved in completing a task and the knowledge required to complete the task. Instead, this cognitive approach tends to focus on constructs such as working memory and self-regulation, and to some extent, problem solving.

Stage theory models that describe processes in terms of the transfer of information from long-term memory to working memory. They do not consider basic concepts accepted in cognitive science such as spreading activation and parallel processing. As such, stage theory models are outdated (MacKay, 1998). In order to progress as a field, writing theorists must consider the complexities of the writing process in terms of the underlying cognitive and social processes (e.g., Newell, Beach, Smith, \& Vanderheide, 2011), as well as the parallel interplay between the various factors that influence writing.

Numerous models have been developed describe comprehension at various levels (e.g., Gernsbacher, 1997; Graesser, Singer, \& Trabasso, 1994; Kintsch, 1998; Myers \& O’Brien, 1998; Zwaan, Langston, \& Graesser, 1995). Although these models diverge in their specific characteristics, a principle focus of the majority of contemporary models rests on the constructive and active nature of the reading process. Following this perspective, text comprehension relies not only on the prior knowledge of the reader, but importantly, also on the processes needed to capitalize on this knowledge. This critical feature of text comprehension can additionally be applied to the process of text production (Genlott \& Grönlund, 2013). Indeed, we have recently argued that the information we have gleaned from years of research on the text comprehension process should be used to inform further research on writing (McNamara \& Allen, 2018).

\section{Interventions to Improve Writing}

To gain writing proficiency, students must develop an understanding of core writing processes (e.g., idea generation, translation, and refinement) along with learning how to coordinate and integrate these processes (Braaksma, Rijlaarsdam, van den Bergh, \& van Hout-Wolters, 2004; Olive, 2014). Educators can support such knowledge and skill acquisition through strategy-based instruction (Graham, Harris, \&, Chambers, 2016; Graham \& Perin, 2007; Newell et al., 2011). Importantly, students must then hone their understanding and skill with such strategies via mindful, self-regulated practice (Kellogg, 2008; Kellogg \& Raulerson, 2009; Kellogg \& Whiteford, 2009) guided by meaningful formative feedback (Parr \& Timperley, 2010; Roscoe ref on feedback).

Multiple studies have demonstrated the benefits of instruction that emphasizes strategies and self-regulation (e.g., Self-Regulated Strategy Development; Graham \& Perin, 2007; Graham et al., 2016; Harris, \& Graham, 2016, 2017). Interventions can support writers of varying ages and abilities by communicating the underlying declarative knowledge of writing (e.g., knowledge about genres and goals) and the procedural knowledge to succeed in writing tasks (e.g., methods for composing valid arguments, organizing ideas cohesively, and elaborating). Strategy instruction interventions benefit college students (e.g., Butler \& Britt, 2011; MacArthur, Philippakos, \& Ianetta, 2015), middle and high school students (e.g., De La Paz \& Felton, 2010; Graham \& Perin, 2007), and elementary school students (e.g., De La Paz \& Sherman, 2013; Ferretti, Lewis, \& Andrews-Weckerly, 2009), and seem particularly helpful for students with weaker skills or learning disabilities.

With respect to practice, there are multiple approaches available including both essay-based and game-based practice (Roscoe, Allen, \& McNamara, 2019). Composing and revising complete essays is the most traditional and common format. Students are typically assigned a writing prompt that asks them to explain a topic, articulate and defend a point of view, or construct a narrative. Students then submit their writing to instructors, peers, or an even automated system for grading and feedback (Dikli \& Bleyle, 2014; Parr \& Timperley, 2014; Patchan, Charney, \& Schunn, 2009; Wingate, 2010). Across iterations of writing and revising, students ideally gain proficiency with deploying, integrating, and refining key writing strategies and skills in an authentic manner. Most automated writing evaluation (AWE) systems, such as Writing Mentor (Burstein et al., 2018), Criterion (Burstein, Tetrault, \& Madnani, 2013), WriteToLearn (Foltz, Streeter, Lochbaum, \& Landauer, 2013), and PEG Writing (Wilson \& Czik, 2016; Wilson, Olinghouse, \& Andrada, 2014) support this form of practice with 
moderate success (e.g., Stevenson \& Phakiti, 2014; Wilson \& Roscoe, 2019),

The strength of essay-based practice also introduces challenges-students must enact and coordinate multiple writing processes (e.g., ideation, translation, and revising) while simultaneously trying to develop those abilities. Many novice writers are overwhelmed and disheartened. In response, game-based practice offers another path for writing strategy practice that aims to leverage the fun and enjoyment of digital games (Habgood \& Ainsworth, 2011; Jackson \& McNamara, 2013; Proske et al., 2014). Although games do not guarantee improved motivation (see Wouters, van Nimwegen, van Oostendorp, \& van der Spek, 2013), they nonetheless can leverage learners' intrinsic enjoyment of play to encourage positive attitudes toward learning tasks (Ryan, Rigby, \& Przybylski, 2006). Specifically, practice activities (e.g., generating topic sentences or constructing an outline) can be embedded within game features and narratives (e.g., building robots or solving a puzzle) to make them more engaging. Various researchers and educators have successfully incorporated digital games in writing instruction (Colby, 2017), such as motivating writing via mystery-solving narratives (e.g., Barab, Pettyjohn, Gresalfi, Volk, \& Solomou, 2012; Dickey, 2011) and world-building tools (e.g., Liao, Chang, \& Chan, 2018). Relative to non-game comparisons, students who write and practice with digital games demonstrate improved writing and/or writing motivation.

\section{Overview of Writing Pal}

Based on prior research and best practices for writing instruction (e.g., Graham \& Perin, 2007), we have developed and tested the Writing Pal (W-Pal), an intelligent tutoring system (ITS) and automated writing evaluation (AWE) system to support adolescent writers (Crossley, Allen, \& McNamara, 2016; Roscoe \& McNamara, 2013; Roscoe, Allen, Weston, Crossley, \& McNamara, 2014). The primary focus of this instructional tool has been argumentbased, persuasive writing. A crucial element of W-Pal's effectiveness is that it synthesizes multiple researchbased instructional approaches, including multimedia strategy instruction, game-based strategy practice, and essay writing practice with formative feedback.

To introduce core writing strategy knowledge, W-Pal includes a series of multimedia lessons in which animated characters present and demonstrate strategies for planning, drafting, and revising essays. Specifically, W-Pal lessons span eight content modules: Prewriting, Planning, Introduction Building, Body Building, Conclusion Building, Paraphrasing, Cohesion Building, and Revising. Each module comprises four to five lessons on individual strategies such as "threading" (i.e., a way to build cohesion by linking ideas across sentences) and "freewriting" (i.e., a way to generate ideas before writing). All lessons were developed based on empirical principles of multimedia design, such as spatial and temporal contiguity, pacing, and partial redundancy (e.g., Mayer, 2017; Mayer \& Moreno, 2003). Evaluations have shown that students are able to recall and apply the information provided in the lessons (e.g., Roscoe, Allen, \& McNamara, 2019; Roscoe, Jacovina, Harry, Russell, \& McNamara, 2015; Roscoe, Novak, King, \& Patchan, 2018).

The AWE core of W-Pal offers a robust system for students to compose original, prompt-based essays, rapidly receive automated summative and formative feedback, and then iteratively revise and improve their essays. Essays submitted to W-Pal receive a holistic score on a 6-point scale from 1 ("Poor") to 6 ("Great") along with actionable recommendations for improved writing and strategies based on the lessons. For example, essays that offer insufficient and vague argument support (i.e., weak body paragraphs) might receive suggestions for generating ideas and incorporating further fact-based evidence. Similarly, paraphrasing recommendations might suggest strategies for condensing and rewording sentences. Studies of writing and revising with such automated feedback have demonstrated modest yet measurable gains writing quality, and have demonstrated that students incorporate lower-level and superficial edits (e.g., spelling and wording) as well as higher-level and substantive edits (e.g., cohesion and elaboration) (McCarthy, Roscoe, Likens, \& McNamara, 2019; Roscoe, Allen, Johnson, \& McNamara, 2018). (Roscoe et al., 2019).

W-Pal also includes a suite of educational mini-games that afford deliberate and engaging practice of individual strategies or combinations of strategies. Each module is associated with at least one game and often two or three games-nearly 40 practice games in total. For example, the Planning module includes Mastermind Outline wherein players practice creating outlines using a drag-and-drop interface, and Planning Passage wherein players take a "road trip" to practice planning the flow of their essays. Research on W-Pal games has observed that students can improve both their writing strategy knowledge and their attitudes and self-efficacy toward writing (e.g., Allen et al., 2014; Proske, Roscoe, \& McNamara, 2014; Roscoe et al., 2019; Roscoe, Brandon, Snow, 
\& McNamara, 2014). Whereas practice and feedback in writing essays is helpful for relatively skilled students, lessskilled students tend to gain more from game-based writing practice which can break the task up into more tangible tasks within a motivating context (Roscoe et al., 2019).

\section{Discussion}

In this paper, we have discussed comprehension and writing from the perspective of text and discourse theories. One important consideration we have conveyed is that prior knowledge, and the use of knowledge and common sense is key to comprehension. It is important to note, however, that prior knowledge is not always beneficial. Students often possess inaccurate information, or misconceptions (Vosniadou \& Brewer, 1992). Misconceptions are resistant to change (Alvermann, \& Smith, \& Readence, 1985) and can interfere with accurate mental model construction (Feltovich, Coulson, \& Spiro, 2001; Kendeou \& van den Broek, 2005). Prior knowledge is also not a unidimensional construct. The nature of a reader's prior knowledge, or how that knowledge is assessed can impact the relation between prior knowledge and comprehension performance (Alexander, Kulikowich, \& Schulze; 1994; McCarthy et al., 2018).

Our attempt here has been to emphasize that literacy is multidimensional. Literacy entails more than simply decoding words and sentences when reading, and requires more than correct spelling and grammatical sentences when writing (Fugelsang, 1982). Literacy has multiple aspects and consequences, including health (Berkman, Sheridan, Donahue, Halper, \& Crotty., 2011; Ratzan \& Parker, 2000).

A literate individual engages in complex, higher-order processes of comprehension and sense-making. Literacy involves multiple layers, including words and phrases, as well as the deeper meaning embedded within social and communicative context. Literacy is by definition a social activity: reading and writing are culturally defined social activities. Literacy involves reading and writing, as well as other skills such as the ability to process graphics, numbers, multimedia, and social media.). Tutoring technologies such as iSTART and W-Pal enhance literacy because they are adaptive to the individual, focus on multiple levels of comprehension and writing, and provide automated summative and formative feedback based on theories of text and discourse. However, they are only effective to the extent that they are part of a community of learners, integrated within a social, communicative context, for purposeful, goal-directed activities. Text and discourse inherently represent values and views. We learn reading and writing through social relations, with parents, teachers, friends, media, and so on. As such, literary activities in classrooms and the community are crucial.

\section{Acknowledgements}

This project was funded by the Institute of Education Sciences, U.S. Department of Education, through Grants R305A130124, R305A120707, R305A180261, R305A180144, R305A190050, and the Office of Naval Research, through Grant N00014140343, N000141712300, to Arizona State University. The opinions expressed are those of the authors and do not represent views of the Institute, the U.S. Department of Education, or the Office of Naval Research.

\section{References}

Alexander, P. A., Kulikowich, J. M., \& Schulze, S. K. (1994). The influence of topic knowledge, domain knowledge, and interest on the comprehension of scientific exposition. Learning and Individual Differences, 6(4), 379-397. https:// doi.org/10.1016/1041-6080(94)90001-9

Allen, L. K., Crossley, S. A., Snow, E. L., \& McNamara, D. S. (2014). Game-based writing strategy tutoring for second language learners: Game enjoyment as a key to engagement. Language Learning and Technology, 18, 124-150.

Allen, L. K., Snow, E. L., Crossley, S. A., Jackson, G. T., \& McNamara, D. S. (2014). Reading comprehension components and their relation to writing. L'Annee Psychologique, 114(4), 663-691.https://doi.org/10.4074/S0003503314004047

Alvermann, D. E., Smith, L. C., \& Readence, J. E. (1985). Prior knowledge activation and the comprehension of compatible and incompatible text. Reading Research Quarterly, 20(4), 420-436. https://doi.org/10.2307/747852

Baker, L., (1996). Social influences on metacognitive development in reading. In C. Cornoldi \& J. Oakhill (Eds.), Reading comprehension difficulties (pp. 331-352). Mahwah, NJ: Erlbaum.

Balyan, R., McCarthy, K. S., \& McNamara, D. S. (2018). Comparing Machine Learning Classification Approaches 


\section{LITERACY: FROM THE PERSPECTIVE OF TEXT AND DISCOURSE THEORY}

for Predicting Expository Text Difficulty. In Proceedings of 31th International Flairs Conference. (pp. 421-426). Melbourne, FL: AAAI Publications.

Barab, S., Pettyjohn, P., Gresalfi, M., Volk, C., \& Solomou, M. (2012). Game-based curriculum and transformational play: Designing to meaningfully positioning person, content, and context. Computers \& Education, 58(1), 518533. https://doi.org/10.1016/j.compedu.2011.08.001

Baumann, J. F., Seifert-Kessell, N. \& Jones, L. A. (1992). Effect of think-aloud instruction on elementary students' comprehension monitoring abilities. Journal of Reading Behavior, 24, 143-172. https://doi. org/10.1080/10862969209547770

Bawden, D. (2008). Origins and concepts of digital literacy. Digital Literacies: Concepts, Policies and Practices, 30, 1732.

Bereiter, C., \& Bird, M. (1985). Use of thinking aloud in identification and teaching of reading comprehension strategies. Cognition and Instruction, 2, 131-156. Retrieved from www.jstor.org/stable/3233543

Berkman, N. D., Sheridan, S. L., Donahue, K. E., Halpern, D. J., \& Crotty, K. (2011). Low health literacy and health outcomes: An updated systematic review.Annals of Internal Medicine, 155(2), 97-107.https://doi.org/10.7326/00034819-155-2-201107190-00005

Bisra, K., Liu, Q., Nesbit, J.C., Salimi, F., \& Winne, P.H.(2018). Inducing self-explanation: A meta-analysis.Educational Psychology Review, 30, 703-725. https://doi.org/10.1007/s10648-018-9434-X

Braaksma, M. A. H., Rijlaarsdam, Van den Bergh, H., \& van Hout-Wolters, B. H. A. M. (2004). Observational learning and its effects on the orchestration of writing processes. Cognition and Instruction, 22(1), 1-36. https://doi. org/10.1207/s1532690Xci2201_1

Burstein, J., Elliot, N., Klebanov, B. B., Madnani, N., Napolitano, D., Schwartz, M., Houghton, P., \& Molloy, H. (2018). Writing Mentor ${ }^{\mathrm{TM}}$ : Writing progress using self-regulated writing support. Journal of Writing Analytics, 2, 285-313.

Burstein, J., Tetreault, J., \& Madnani, N. (2013). The E-rater ${ }^{\circledR}$ automated essay scoring system. In M. D. Shermis \& J. Burstein (Eds.), Handbook of automated essay evaluation: Current applications and new directions (pp. 77-89). New York, NY: Routledge.

Butler, J. A., \& Britt, M. A. (2011). Investigating instruction for improving revision of argumentative essays. Written Communication, 28(1), 70-96. https://doi.org/10.1177/0741088310387891

Chi, M. T. H., Bassok, M., Lewis, M. W., Reimann, P., \& Glaser, R. (1989). Self-explanations: How students study and use examples in learning to solve problems. Cognitive Science, 13, 145-182. https://doi.org/10.1016/03640213(89)90002-5

Colby, R. S. (2017). Game-based pedagogy in the writing classroom. Computers and Composition, 43, 55-72. https:// doi.org/10.1016/j.compcom.2016.11.002

Cree, A., Kay, A., \& Steward, J. (2012). The economic and social cost of illiteracy: A snapshot of illiteracy in a global context. Retrieved from http://hdl.voced.edu.au/10707/321997

Crossley, S. A., Allen, L. K., \& McNamara, D. S. (2016). The writing pal: A writing strategy tutor. In S. A. Crossley \& D. S. McNamara (Eds.), Adaptive educational technologies for literacy (pp. 204-224). New York, NY: Routledge.

Decker, B. C. (1986). Aliteracy: What teachers can do to keep Johnny reading. Journal of Teacher Education, 37(6), 55-58. https://doi.org/10.1177/002248718603700609

De La Paz, S., \& Felton, M. K. (2010). Reading and writing from multiple source documents in history: Effects of strategy instruction with low to average high school writers. Contemporary Educational Psychology, 35(3), 174192. https://doi.org/10.1016/j.cedpsych.2010.03.001

De La Paz, S., \& Sherman, C. K. (2013). Revising strategy instruction in inclusive settings: Effects for English learners and novice writers. Learning Disabilities Research \& Practice, 28(3), 129-141. https://doi.org/10.1111/ldrp.12011

Dickey, M. D. (2011). Murder on Grimm Isle: The impact of game narrative design in an educational game-based learning environment. British Journal of Educational Technology, 42(3), 456-469. https://doi.org/10.1111/j.14678535.2009.01032.x

Dikli, S., \& Bleyle, S. (2014). Automated essay scoring feedback second language writers: How does it compare to instructor feedback? Assessing Writing, 22, 1-17. https://doi.org/10.1016/j.asw.2014.03.006

Eshet, Y. (2004). Digital literacy: A Conceptual framework for survival skills in the digital era. Journal of Educational Multimedia and Hypermedia, 13(1), 93-106.

Feltovich, P. J., Coulson, R. L., \& Spiro, R. J. (2001). Learners'(mis)understanding of important and difficult concepts: A challenge to smart machines in education. In K. D. Forbus \& P. J. Feltovich (Eds.), Smart machines in education (pp. 349-375). Cambridge, MA: MIT Press.

Ferretti, R. P., Lewis, W. E., \& Andrews-Weckerly, S. (2009). Do goals affect the structure of students' argumentative writing strategies?. Journal of Educational Psychology, 101(3), 577-589. https://doi.org/10.1037/a0014702

Fitzgerald, J., \& Shanahan, T. (2000). Reading and writing relations and their development. Educational Psychologist, 35(1), 39-50. https://doi.org/10.1207/S15326985EP3501_5 
Flower, L., \& Hayes, J. R. (1981). A cognitive process theory of writing. College Composition and Communication, 32(4), 365-387. https://doi.org/10.2307/356600

Foltz, P. W., Streeter, L. E., Lochbaum, K. E., \& Landauer, T. K. (2013). Implementation and applications of the Intelligent Essay Assessor. In M. D. Shermis \& J. Burstein (Eds.), Handbook of automated essay evaluation: Current applications and new directions (pp. 68-88). New York, NY: Routledge.

Fugelsang, A. (1982). About understanding: Ideas and observations on cross-cultural communication. Uppsala, Sweden: Dag Hammarskjöld Foundation.

Genlott, A. A., \& Grönlund, Å. (2013). Improving literacy skills through learning reading by writing: The iWTR method presented and tested. Computers \& Education, 67, 98-104. https://doi.org/10.1016/j.compedu.2013.03.007

Graff, H. J. (1987). The legacies of literacy: Continuities and contradictions in western culture and society (vol. 598). Indiana, IN: Indiana University Press.

Graff, H. J. (2017). Literacy myths, legacies, and lessons: New studies on literacy. New Brunswick, NJ: Transaction publishers.

Habgood, M. J., \& Ainsworth, S. E. (2011). Motivating children to learn effectively: Exploring the value of intrinsic integration in educational games. The Journal of the Learning Sciences, 20(2), 169-206. https://doi.org/10.1080/1 0508406.2010.508029

Hansen, J., \& Pearson, P. (1983). An instructional study: Improving the inferential comprehension of good and poor fourth-grade readers. Journal of Educational Psychology, 75, 821-829. https://doi.org/10.1037/0022-0663.75.6.821

Hayes, J. R. (2012). Modeling and remodeling writing. Written Communication, 29(3), 369-388. https://doi. org/10.1177/0741088312451260

Graham, S., Harris, K. R., \& Chambers, A. B. (2016). Evidence-based practice and writing instruction. In C. A. MacArthur, S. Graham \& J. Fitzgerald (Eds.), Handbook of writing research (2 ${ }^{\text {nd }}$ ed., pp. 211-226). New York, NY: Guilford Press.

Graham, S., Liu, X., Bartlett, B., Ng, C., Harris, K. R., Aitken, A.,... Talukdar, J. (2018). Reading for writing: A metaanalysis of the impact of reading interventions on writing. Review of Educational Research, 88(2), 243-284. https:// doi.org/10.3102/0034654317746927

Graham, S., \& Perin, D. (2007). A meta-analysis of writing instruction for adolescent students. Journal of Educational Psychology, 99(3), 445-476. https://doi.org/10.1037/0022-0663.99.3.445

Hanemann, U. (2015a). The evolution and impact of literacy campaigns and programmes, 2000-2014. UIL Research Series: No. 1. Hamburg, Germany: UNESCO Institute for Lifelong Learning.

Lind, A. (2008). Literacy for all: Making a difference. Paris, France: UNESCO-IIEP. Retrieved from http://unesdoc. unesco.org/images/0015/001597/159785e.pdf

Hanemann, U. (2015b). Lifelong literacy: Some trends and issues in conceptualising and operationalising literacy from a lifelong learning perspective. International Review of Education, 61(3), 295-326. https://doi.org/10.1007/ s11159-015-9490-0

Harris, K. R., \& Graham, S. (2016). Self-Regulated strategy development in writing: Policy implications of an evidence-based practice. Policy Insights from the Behavioral and Brain Sciences, 3(1), 77-84. https://doi. org/10.1177/2372732215624216

Harris, K. R., \& Graham, S. (2017). Self-Regulated Strategy Development: Theoretical bases, critical instructional elements, and future research. In R. Fidalgo \& T. Olive, R. Fidalgo, K. R. Harris, \& M. Braaksma (Eds.), Studies in writing series (vol. 34: Design principles for teaching effective writing, pp. 119-151). Leiden, Germany: Brill.

Jackson, T. G., Boonthum, C., \& McNamara, D. S. (2015). Natural Language Processing and game-based practice in iSTART. Journal of Interactive Learning Research, 26, 189-208. Retrieved from https://files.eric.ed.gov/fulltext/ ED577164.pdf

Jackson, G.T., \& McNamara, D.S. (2012). Applying NLP metrics to students' self-explanations. In P.M. McCarthy \& C. Boonthum-Denecke (Eds.), Applied natural language processing and content analysis: Identification, investigation, and resolution (pp. 261-275). Hershey, PA: IGI Global.

Jackson, G. T., \& McNamara, D. S. (2013). Motivation and performance in a game-based intelligent tutoring system. Journal of Educational Psychology, 105, 1036-1049. https://doi.org/10.1037/a0032580

Johnson, A. M., Guerrero, T. A., Tighe, E. L., \& McNamara, D. S. (2017). iSTART-ALL: Confronting adult low literacy with intelligent tutoring for reading comprehension. In B. Boulay, R. Baker \& E. Andre (Eds.), Proceedings of the 18th International Conference on Artificial Intelligence in Education (pp. 125-136). Wuhan, China: Springer.

Johnson, A. M., McCarthy, K. S., Kopp, K., Perret, C. A., \& McNamara, D. S. (2017). Adaptive reading and writing instruction in iSTART and W-Pal. In Z. Markov \& V. Rus (Eds.), Proceedings of the 30th Annual Florida Artificial Intelligence Research Society International Conference. Marco Island, FL: AAAI Press.

Kellogg, R. T. (2008). Training writing skills: A cognitive development perspective. Journal of Writing Research, 1(1), 1-26. https://doi.org/10.17239/jowr-2008.01.01.1 
Kellogg, R. T., \& Raulerson, B. A. (2007). Improving the writing skills of college students. Psychonomic Bulletin and Review, 14(2), 237-242. https://doi.org/10.3758/BF03194058

Kellogg, R. T., \& Whiteford, A. P. (2009). Training advanced writing skills: The case for deliberate practice. Educational Psychologist, 44(4), 250-266. https://doi.org/10.1080/00461520903213600

Kendeou, P. A., \& Van Den Broek, P. (2005). The effects of readers' misconceptions on comprehension of scientific text. Journal of Educational Psychology, 97(2), 235-245. https://doi.org/10.1037/0022-0663.97.2.235

Liao, C. C., Chang, W. C., \& Chan, T. W. (2018). The effects of participation, performance, and interest in a game-based writing environment. Journal of Computer Assisted Learning, 34(3), 211-222. https://doi.org/10.1111/jcal.12233

Luke, A. F., \& Peter. (1997). The social practices of reading. In P. F, Sandra Muspratt \& Allan Luke (Eds.), Constructing critical literacies (pp. 185-225). New Jersey, NJ: Hampton Press.

MacArthur, C. A., Philippakos, Z.A., \& Ianetta, M. (2015). Self-regulated strategy instruction in college developmental writing. Journal of Educational Psychology, 107(3), 855-867. https://doi.org/10.1037/edu0000011

Magliano, J. P., Todaro, S. Millis, K., Wiemer-Hastings, K., Kim, H. J., \& McNamara, D. S. (2005). Changes in reading strategies as a function of reading training: A comparison of live and computerized training. Journal of Educational Computing Research, 32, 185-208. https://doi.org/10.2190/1LN8-7BQE-8TN0-M91L

Jee, B. D., \& Wiley, J. (2007). How goals affect the organization and use of domain knowledge. Memory \& Cognition, 35, 837-851. https://doi.org/10.3758/BF03193459

Kaakinen, J. K., \& Hyona, J. (2007). Perspective effects in repeated reading: An eye movement study. Memory \& Cognition, 35, 1323-1336. https://doi.org/10.3758/BF03193604

Kaakinen, J. K., Hyona, J., \& Keenan, J. M. (2002). Perspective effects on online text processing. Discourse Processes, 33, 159-173. https://doi.org/10.1207/S15326950DP3302_03

Kendeou, P., \& van den Broek, P. (2007). The effects of prior knowledge and text structure on comprehension processes during reading of scientific texts. Memory \& Cognition, 35, 1567-1577. https://doi.org/10.3758/BF03193491

Kirschner, P. A., Sweller, J., \& Clark, R. E. (2006). Why minimal guidance during instruction does not work: An analysis of the failure of constructivist, discovery, problem-based, experiential, and inquiry-based teaching. Educational Psychologist, 41, 75-86. https://doi.org/10.1207/s15326985ep4102_1

Langston, M. C., \& Trabasso, T. (1999). Modeling causal integration and availability of information during comprehension of narrative texts. In H. van Oostendorp \& S. R. Goldman (Eds.), The construction of mental representations during reading (pp. 29-69). Mahwah, NJ: Erlbaum.

Lehman, S., \& Schraw, G. (2002). Effects of coherence and relevance on shallow and deep text processing. Journal of Educational Psychology, 94, 738-750. https://doi.org/10.1037/0022-0663.94.4.738

Linderholm, T., \& Van den Broek, P. (2002). The effects of reading purpose and working memory capacity on the processing of expository text. Journal of Educational Psychology, 94, 778-784. https://doi.org/10.1037/00220663.94.4.778

Lorch, R. F., Jr., \& van den Broek, P. (1997). Understanding reading comprehension: Current and future contributions of cognitive science. Contemporary Educational Psychology, 22, 213-246. https://doi.org/10.1006/ceps.1997.0931

Magliano, J.P., Trabasso, T., \& Graesser, A. C. (1999). Strategic processes during comprehension. Journal of Educational Psychology, 91, 615-629. https://doi.org/10.1037/0022-0663.91.4.615

Magnifico, A. M. (2010). Writing for whom? Cognitive, motivation, and a writer's audience. Educational Psychologist, 45(3), 167-184. https://doi.org/10.1080/00461520.2010.493470

Mayer, R. E. (2017). Using multimedia for e-learning. Journal of Computer-Assisted Learning, 33, 403-423.

Mayer, R.E., \& Moreno, R. (2013). Nine ways to reduce cognitive load in multimedia learning.Educational Psychologist, 38(1), 43-52. https://doi.org/10.1111/jcal.12197

McCarthy, K. S., Likens, A. D., Johnson, A. M., Guerrero, T. A., \& McNamara, D. S. (2018). Metacognitive overload!: Positive and negative effects of metacognitive prompts in an intelligent tutoring system. International Journal of Artificial Intelligence in Education, 28, 420-438. https://doi.org/10.1007/s40593-018-0164-5

McCarthy, K. S., Roscoe, R. D., Likens, A. D., \& McNamara, D. S. (2019). Checking it twice: Does adding spelling and grammar checkers improve essay quality in an automated writing tutor? In S. Isotani et al. (Eds.), Proceedings of the International Conference on Artificial Intelligence in Education (pp. 270-282). Chicago, IL: Springer. https://doi. org/10.1007/978-3-030-23204-7_23

McKoon, G., \& Ratcliff, R. (1998). Memory based language processing: Psycholinguistic research in the 1990s. Annual Review of Psychology, 49, 25-42. https://doi.org/10.1146/annurev.psych.49.1.25

McNamara, D. S., \& Allen, L. K. (2017). Toward an integrated perspective of writing as a discourse process. In M. F. Schober, D. N. Rapp, \& M. A. Britt (Eds.), The Routledge handbook of discourse processes (2 $2^{\text {nd }}$ ed., pp. 362-389). New York, NY: Routledge. https://doi.org/10.4324/9781315687384

McNamara, D. S., Levinstein, I. B., \& Boonthum, C. (2004). iSTART: Interactive strategy training for active reading and thinking. Behavior Research Methods, Instruments, \& Computers, 36(2), 222-233. https://doi.org/10.3758/ 


\section{bf03195567}

McNamara, D. S. \& Magliano, J. P. (2009a). Self-explanation and metacognition: The dynamics of reading. In J. D. Hacker, J. Dunlosky, \& A. C. Graesser (Eds.), Handbook of metacognition in education (pp. 60-81). Mahwah, NJ: Erlbaum.

McNamara, D. S. \& Magliano, J. P. (2009b). Towards a comprehensive model of comprehension. In B. Ross (Ed.), The psychology of learning and motivation (pp. 297-384). New York, NY: Elsevier.

McNamara, D. S., \& O'Reilly, T. (2009). Theories of comprehension skill: Knowledge and strategies versus capacity and suppression. In A. M. Columbus (Ed.), Advances in Psychology research. Hauppauge, NY: Nova Science Publishers, Inc.

McNamara, D. S., O’Reilly, T., Best, R., \& Ozuru, Y. (2006). Improving adolescent students' reading comprehension with iSTART. Journal of Educational Computing Research, 34, 147-171.

Mikulecky, L. (1978, May). Aliteracy and a changing view of reading goals. Paper presented at the Annual Meeting of the International Reading Association (Bouston,Texas).

Mullis, I. V. S., Martin, M. O., Foy, P., \& Drucker, K. T. (2012). PIRLS 2011 International results in reading. Chestnut Hill, MA: TIMSS \& PIRLS International Study Center, Boston College.

Newell, G. E., Beach, R., Smith, J., \& VanDerHeide, J. (2011). Teaching and learning argumentative reading and writing: A review of research. Reading Research Quarterly, 46(3), 273-304.

Olive, T. (2014). Toward a parallel and cascading model of the writing system: A review of research on writing processes coordination. Journal of Writing Research, 6(2), 173-194. https://doi.org/10.17239/jowr-2014.06.02.4

Palincsar, A. S., \& Brown, A. L. (1984). Reciprocal teaching of comprehension-fostering and monitoring activities. Cognition and Instruction, 2, 117-175. https://doi.org/10.1207/s1532690xci0102_1

Palincsar, A. S., \& Brown, A. L. (1986). Interactive teaching to promote independent learning from text. Reading Teacher, 39, 771-777.

Panaite, M., Dascalu, M., Johnson, A., Balyan, R., Dai, J., McNamara, D. S., \& Trausan-Matu, S. (2018). Bring it on! Challenges encountered while building a comprehensive tutoring system using ReaderBench. In C. P. Rosé, R. Martínez-Maldonado, H. U. Hoppe, R. Luckin, M. Mavrikis, K. Porayska-Pomsta, B. McLaren, ... \& B. D. Boulay (Eds.), Proceedings of the International Conference on Artificial Intelligence in Education (part 1, pp. 409-419). Cham, Switzerland: Springer. https://doi.org/10.1007/978-3-319-93843-1_30

Parr, J. M., \& Timperley, H. S. (2010). Feedback to writing assessment for teaching and learning and student progress. Assessing Writing, 15, 68-85.

Patchan, M. M., Charney, D., \& Schunn, C. D. (2009). A validation study of students' end comments: Comparing comments by students, a writing instructor, and a content instructor. Journal of Writing Research, 1(2), 124-152.

Proske, A., Roscoe, R. D., \& McNamara, D. S. (2014). Game-based practice versus traditional practice in computerbased writing strategy training: Effects on motivation and achievement. Educational Technology Research and Development, 62, 481-505. https://doi.org/10.1007/s11423-014-9349-2

Ratzan S. C. \& \& Parker R. M. (2000). National library of medicine current bibliographies in medicine: Health literacy. In C.R. Selden, M. Zorn, S. C. Ratzan, et al. (Eds.), Bethesda, M: National Institutes of Health.

Roscoe, R. D., Allen, L. K., Johnson, A. C., \& McNamara, D. S. (2018). Automated writing instruction and feedback: Instructional mode, attitudes, and revising. In Proceedings of the Human Factors and Ergonomics Society Annual Meeting, 62(1), 2089-2093. https://doi.org/10.1177/1541931218621471

Roscoe, R.D., Allen, L. K., \& McNamara,D. S. (2019). Contrasting writing practice formats in a writing strategy tutoring system. Journal of Educational Computing Research, 57(3), 723-754. https://doi.org/10.1177/07356333118763429

Roscoe, R. D., Allen, L. K., Weston, J. L., Crossley, S. A, \& McNamara, D. S. (2014). The Writing Pal Intelligent Tutoring System: Usability testing and development. Computers and Composition, 34, 39-59. https://doi.org/10.1016/j. compcom.2014.09.002

Roscoe, R. D., Brandon, R., Snow, E. L., \& McNamara, D. S. (2014). Game-based writing strategy practice with the Writing Pal. In K. E. Pytash \& R. E. Ferdig (Eds.), Exploring technology for writing and writing instruction (pp. 1-20). Hershey, PA: IGI Global.

Roscoe, R. D., Jacovina, M. E., Harry, D., Russell, D. G., \& McNamara, D. S. (2015). Partial verbal redundancy in multiple media presentations for writing strategy instruction. Applied Cognitive Psychology, 29, 669-679. https:// doi.org/10.1002/acp.3149

Roscoe, R. D., \& McNamara, D. S. (2013). Writing Pal: feasibility of an intelligent writing strategy tutor in the high school classroom. Journal of Educational Psychology, 105, 1010-1025. https://doi.org/10.1037/a0032340

Roscoe, R.D., Novak, K., King, A., \& Patchan, M. M. (2018). Exploring higher agency roles for learning with educational technology and multimedia. In Proceedings of the Human Factors and Ergonomics Society Annual Meeting, 62(1), 2074-2078. https://doi.org/10.1177/1541931218621468

Roscoe, R. D., Snow, E. L., Allen, L. K., \& McNamara, D. S. (2015). Automated detection of essay revising patterns: 
Applications for intelligent feedback in a writing tutor. Technology, Instruction, Cognition, and Learning, 10, 59-79.

Roscoe, R. D., Wilson, J., Johnson, A. C., \& Mayra, C. R. (2017). Presentation, expectations, and experience: Sources of student perceptions of automated writing evaluation. Computers in Human Behavior, 70, 207-221. https://doi. org/10.1016/j.chb.2016.12.076

Rosenshine, B., \& Meister, C. (1994). Reciprocal teaching: A review of the research. Review of Educational Research, 64, 479-530. https://doi.org/10.3102/00346543064004479

Rosenshine, B., Meister, C., \& Chapman, S. (1996). Teaching students to generate questions: A review of the intervention studies. Review of Educational Research, 66, 181-221. https://doi.org/10.3102/00346543066002181

Ruseti, S., Dascalu, M., Johnson, A. M., Balyan, R., Kopp, K. J., McNamara, D. S., ... \& Trausan-Matu, S. (2018a). Predicting question quality using Recurrent Neural Networks. In Proceedings of the International Conference on Artificial Intelligence in Education (pp. 491-502). Cham, Switzerland: Springer. https://doi.org/10.1007/978-3319-93843-1_36

Ruseti, S., Dascalu, M., Johnson, A. M., McNamara, D. S., Balyan, R., McCarthy, K. S., \& Trausan-Matu, S. (2018b). Scoring summaries using recurrent neural networks. In R. Nkambou, R. Azevedo, \& J. Vassileva (Eds.), Intelligent Tutoring Systems (pp. 191-201). Cham, Switzerland: Springer. https://doi.org/10.1007/978-3-319-91464-0_19

Ryan, R. M., Rigby, C. S., \& Przybylski, A. (2006). The motivational pull of video games: A self-determination theory approach. Motivation and Emotion, 30(4), 344-360. https://doi.org/10.1007/s11031-006-9051-8

Shanahan, T. (2016). Relationships between reading and writing development. In C. A. MacArthur, S. Graham, \& J. Fitzgerald (Eds.), Handbook of writing research (2 ${ }^{\text {nd }}$ ed., pp. 194-207). New York, NY: Guilford Press.

Snow, C. (2002). Reading for understanding: Toward an $R \& D$ program in reading comprehension. Santa Monica, CA: RAND.

Snow, E. L., Jacovina, M. E., Jackson, G. T., \& McNamara, D. S. (2016). iSTART-2: A reading comprehension and strategy instruction tutor. In D.S. McNamara \& S. A. Crossley (Eds.), Adaptive educational technologies for literacy instruction (pp.104-121). Taylor \& Francis, Routledge: NY.

Stevenson, M., \& Phakiti, A. (2014). The effects of computer-generated feedback on the quality of writing. Assessing Writing, 19, 51-65. https://doi.org/10.1016/j.asw.2013.11.007

Street, B. (1984). Literacy in theory and practice. Cambridge, UK: Cambridge University Press.

Trabasso, T., \& Magliano, J. P. (1996). Conscious understanding during comprehension. Discourse Processes, 21(3), 255-287. https://doi.org/10.1080/01638539609544959

UNESCO Institute for Statistics. (2008). International literacy statistics: A review of concepts, methodology, and current data. Montreal, Canada: UNESCO Institute for Statistics.

VanLehn, K., Jones, R. M., \& Chi, M. T. H. (1992). A model of the self-explanation effect. The Journal of the Learning Sciences, 2, 1-59. https://doi.org/10.1207/s15327809jls0201_1

Verhoeven, L. T. (Ed.). (1994). Functional literacy: Theoretical issues and educational implications (vol. 1). Amsterdam, Netherlands: John Benjamins Publishing.

Vosniadou, S. \& Brewer, W.F. (1992). Mental Models of the day/night cycle. Cognitive Science, 18, 123-183. https:// doi.org/10.1016/0364-0213(94)90022-1

Walter, P. (1999). Defining literacy and its consequences in the developing world. International Journal of Lifelong Education, 18(1), 31-48.

Watanabe, M., McCarthy, K.S., \& McNamara, D. S. (2019). Examining the effects of adaptive task selection on students' motivation in an intelligent tutoring system. In Proceedings of the 9th International Conference on Learning Analytics and Knowledge (pp. 161-62). Phoenix, AZ: SOLAR.

Wilson, J., \& Czik, A. (2016). Automated essay evaluation software in English Language Arts classrooms: Effects on teacher feedback student motivation, and writing quality. Computers and Education, 100, 94-109. https://doi. org/10.1016/j.compedu.2016.05.004

Wilson, J., Olinghouse, N. G., \& Andrada, G. N. (2014). Does automated feedback improve writing quality? Learning Disabilities - A Contemporary Journal, 12(1), 93-118. Retrieved from https://www.learntechlib.org/p/153416/

Wilson, J., \& Roscoe, R. D. (2019). Automated writing evaluation and feedback: Multiple metrics of efficacy. Published online at Journal of Educational Computing Research. https://doi.org/10.1177/0735633119830764

Wingate, U. (2010). The impact of formative feedback on the development of academic writing. Assessment and Evaluation in Higher Education, 35(5), 579-533. https://doi.org/10.1080/02602930903512909

Wouters, P., Van Nimwegen, C., Van Oostendorp, H., \& Van Der Spek, E. D. (2013). A meta-analysis of the cognitive and motivational effects of serious games. Journal of Educational Psychology, 105(2), 249-265. https://doi. org/10.1037/a0031311

Yuill, N., \& Oakhill, J. (1988). Understanding of anaphoric relations in skilled and less skilled comprehenders. British Journal of Psychology, 79, 173-186. https://doi.org/10.1111/j.2044-8295.1988.tb02282.x 